\title{
Immediate breast reconstruction using the free lumbar artery perforator flap and lateral thoracic vein interposition graft for recipient lateral thoracic artery anastomosis
}

\author{
Toshihiko Satake, Reiko Nakasone, Shinji Kobayashi ${ }^{1}$, Jiro Maegawa ${ }^{2}$ \\ Department of Plastic and Reconstructive Surgery, Yokohama City University Medical Center, ${ }^{1}$ Department of Plastic and \\ Reconstructive Surgery, Kanagawa Children's Medical Center, ${ }^{2}$ Department of Plastic and Reconstructive Surgery, Yokohama \\ City University Hospital, Yokohama, Kanagawa, Japan
}

Address for correspondence: Dr. Toshihiko Satake, 4-57 Urafune-cho, Minami-ku, Yokohama, Kanagawa 232-0024, Japan. E-mail: toshi@yokohama-cu.ac.jp

\section{ABSTRACT}

The lumbar artery perforator (LAP) flap, which contains excess skin and fat tissue, love handles, that extends from the lower back to upper buttock, may provide an alternate tissue source for autologous breast reconstruction. However, LAP flap use during this procedure frequently requires vessel interposition grafts to correct the short flap pedicle length and mismatched recipient vessel calibre. A 46-year-old patient underwent a right nipple-sparing mastectomy using a lateral approach for ductal carcinoma in situ and immediate LAP flap breast reconstruction. The lateral thoracic vessel served as the recipient vessel, and a lateral thoracic vein interposition graft from the distal remnant was performed to adjust the arterial length and size discrepancy between the recipient lateral thoracic artery and pedicle artery. This procedure facilitates microsurgical anastomosis and medialisation of LAP flap to make a natural decollete line and create a cleavage for the reconstructed breast.

\section{KEY WORDS}

Autologous breast reconstruction; free flap; lateral thoracic vessel; lumbar artery perforator flap; vein interposition graft

\section{INTRODUCTION}

he lumbar artery perforator (LAP) flap provides excess skin and subcutaneous fat tissue from the lower back to upper buttock, known as 'love handles', without removing any donor muscle. Moreover, the donor-site post-operative scar can be hidden with

\begin{tabular}{|l|l|}
\hline \multicolumn{2}{|c|}{ Access this article online } \\
\hline Quick Response Code: & Website: \\
\hline & www.ijps.org \\
\cline { 2 - 2 } & Dol: \\
\hline
\end{tabular}

high-rise underwear. The free LAP flap has recently been reported an alternative donor tissue source for autologous breast reconstruction in patients who are not candidates for a deep inferior epigastric artery perforator (DIEP)

This is an open access article distributed under the terms of the Creative Commons Attribution-NonCommercial-ShareAlike 3.0 License, which allows others to remix, tweak, and build upon the work non-commercially, as long as the author is credited and the new creations are licensed under the identical terms.

For reprints contact: reprints@medknow.com

How to cite this article: Satake T, Nakasone R, Kobayashi S, Maegawa J. Immediate breast reconstruction using the free lumbar artery perforator flap and lateral thoracic vein interposition graft for recipient lateral thoracic artery anastomosis. Indian J Plast Surg 2016;49:91-4. 
or superficial inferior epigastric artery (SIEA) flap..$^{[1,2]}$ There are only two reports on the usage of LAP flap during this procedure because it requires frequent vessel interposition grafting to correct the short flap pedicle length and mismatched calibre size of the recipient vessel. $^{[2]}$

This article reports a case of immediate breast reconstruction using LAP flap and recipient lateral thoracic vessel anastomosis. During microsurgical anastomosis, a lateral thoracic vein interposition graft from the distal remnant was used to overcome the arterial length and size discrepancy present between the recipient and pedicle artery.

\section{CASE REPORT}

A 46-year-old nulliparous patient presented with ductal carcinoma in situ (DCIS) of the right breast after medical examination. She required a nipple-sparing mastectomy (NSM) to eliminate the multifocal and widespread lesion, but hoped for immediate breast reconstruction using her own tissue. We initially estimated that her abdominal tissue was an adequate donor site for DIEP or SIEA flap harvesting [Figure 1]. She had planned for a future pregnancy with natural childbirth. According to the patient's wishes, we planned to use a superior gluteal artery perforator (GAP) flap for reconstruction. Pre-operative computed tomography-angiography showed poor visualisation of the large gluteal perforators [Figure 2]. However, we instead detected L2, L3 and L4 large LAPs. The patient underwent right NSM plus sentinel lymph node

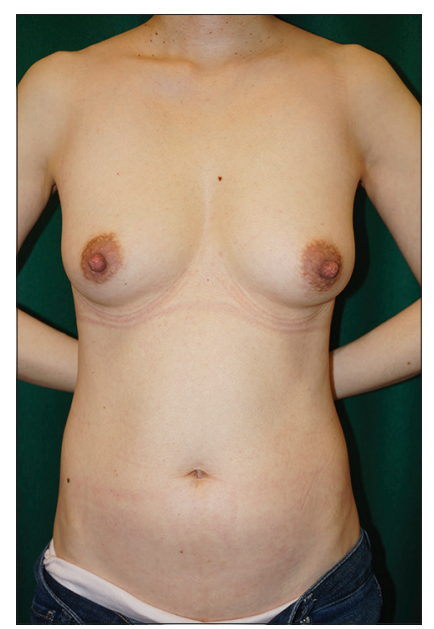

Figure 1: A 46-year-old nulliparous female (body mass index, $17.2 \mathrm{~kg} / \mathrm{m}^{2}$; bra cup size, E) presented with ductal carcinoma in situ of the right breast biopsy (SNB) and immediate breast reconstruction using the free LAP flap.

After NSM and SNB were complete, the patient was positioned prone. A horizontal fusiform skin paddle measuring $6.0 \mathrm{~cm} \times 16.5 \mathrm{~cm}$ of the right LAP flap was incised and then the adipose lobe including the flap was extended both superiorly and more inferiorly to obtain the required volume of transferrable tissue [Figure 3a]. We incised thoracolumbar fascia and confirmed the presence of 3 (L2, L3 and L4) LAPs located between the erector spinae and the quadratus lumborum muscles. Among these vessels, the L2 LAP was the largest and ran obliquely and deeply towards its origin, which was advantageous for microsurgical anastomosis [Figure 3b].

The harvested LAP flap had sufficient volume to reconstruct the breast and weighed $334 \mathrm{~g}$, exceeding the $211 \mathrm{~g}$ mastectomy weight. The flap pedicle was $3.0 \mathrm{~cm}$ in length and comprised one artery and one venae comitantes. The external calibres of the lumbar artery and concomitant vein were 1.6 and $1.9 \mathrm{~mm}$, respectively. The donor site wound was closed primarily using a closed suction drain.

The patient was again placed in the supine position. The lateral thoracic vessel was selected as the recipient vessel and venous drainage was accomplished with end-to-end anastomosis. However, the lateral thoracic artery at the same level as venous anastomosis was $0.6 \mathrm{~mm}$ in diameter, yielding an external calibre ratio between the recipient and flap arteries in excess of 1:2. Given this difference, anastomosis seemed difficult. We used a remnant of the

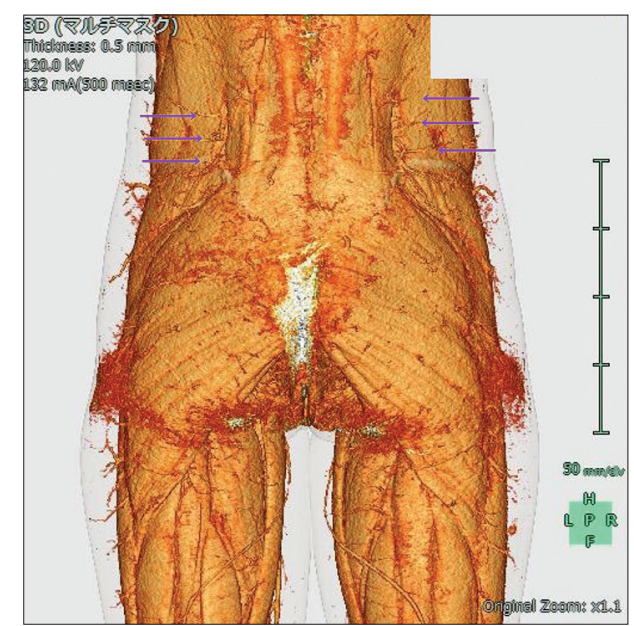

Figure 2: Pre-operative computed tomography-angiography showed poor visualisation of the large gluteal perforators, but alternate detection of the $L 2$, L3 and L4 large lumbar artery perforators 
lateral thoracic vein as an interposition graft to adjust for discrepancy in arterial length and size between the lateral thoracic artery and pedicle artery [Figure $4 \mathrm{a}$ and b].

After microsurgery, the denuded LAP flap was placed onto the pectoralis major muscle in a position parallel to the primary donor site to reconstruct the lower pole of the breast using the extended upper buttock tissue. The total operating time including mastectomy was $10 \mathrm{~h}$ 30 min, with 2 h 51 min for flap ischaemia. The patient's post-operative course was uneventful [Figure $5 a$ and b].

\section{DISCUSSION}

Use of LAP flap was first reported by Kato et al. in 1999. ${ }^{[3]}$ Since then, this procedure has been utilised mainly for lumbosacral reconstruction using a pedicled flap or for breast reconstruction using a free flap. ${ }^{[1-4]}$ There are several anatomical studies on LAP number, location,

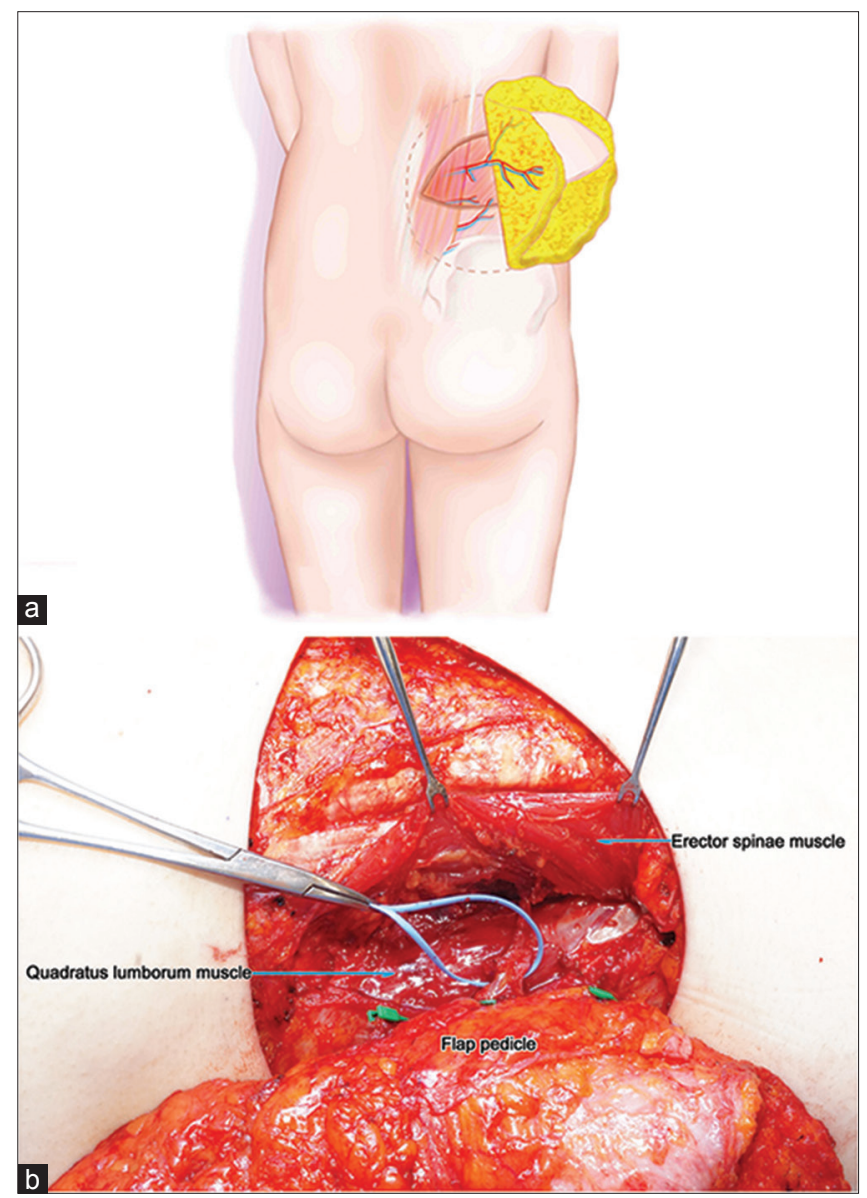

Figure 3: (a) A horizontal fusiform skin paddle of lumbar artery perforator flap was incised first, and then the adipose lobe that included the flap was extended both superiorly and more inferiorly to obtain the required volume of transferrable tissue, (b) from among the 3 (L2, L3 and L4) lumbar artery perforators, the L2 was the largest and ran both obliquely and deeply towards its origin between the erector spinae and the quadratus lumborum muscles diameter and vascular territory. ${ }^{[3,5-7]}$ There are $6 \pm 2$ perforators on each side, with three pairs of superior perforators passing between the erector spinae and the quadratus lumborum muscles. ${ }^{[5]}$ L2 and L4 perforators tended to be of a larger calibre, with the $\mathrm{L} 4$ perforator often coursing septocutaneously. ${ }^{[3,7]}$

In 2015, there was a report from Belgium of a large series of patients treated with LAP flap breast reconstruction. ${ }^{[2]}$ They often used recipient internal mammary vessels with deep inferior epigastric vessels as an interposition graft to extend the donor pedicle length or to enlarge anastomosis size. This procedure may eliminate the use of DIEP flap and leave an additional abdominal scar. Six of 35 flaps reported in that series had to be re-explored for venous thromboses. This problem could be avoided in future by establishing a safer alternative breast reconstruction procedure.

NSM using a lateral vertical approach saves the integrity of skin blood supply, allows for a complete breast grand removal and facilitates improved cosmetic results for the breast cancer patients with this indication. ${ }^{[8]}$ The

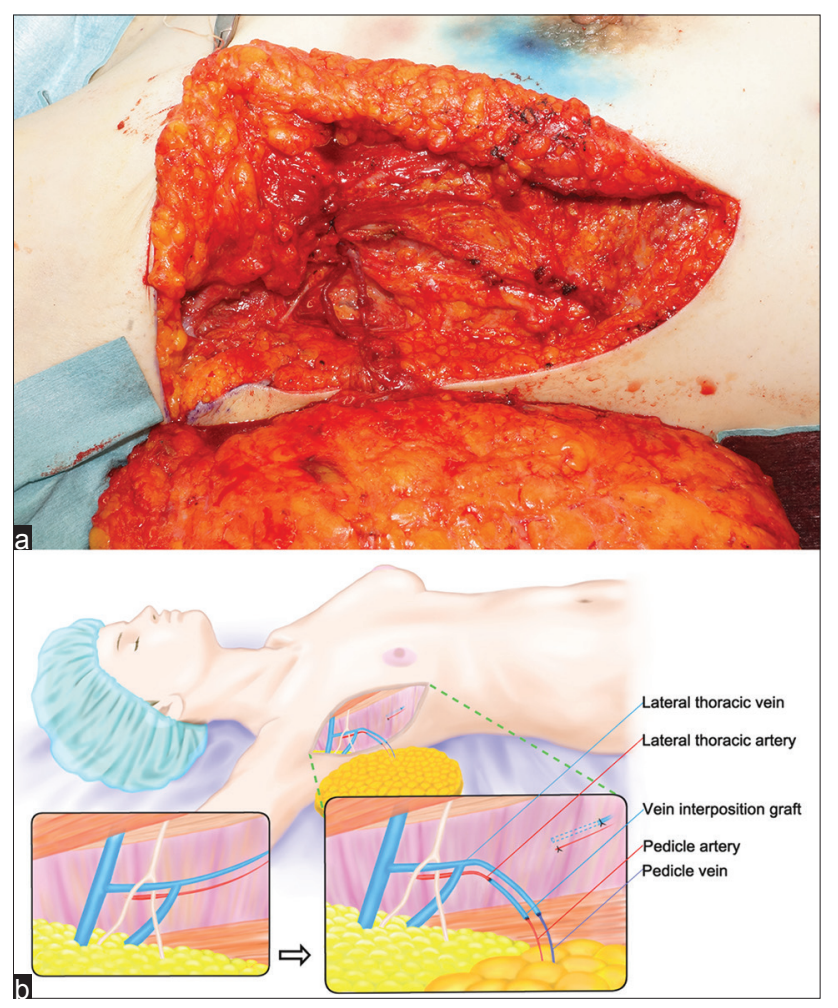

Figure 4: (a) Selection of the lateral thoracic vessel as the recipient vessel with a vein interposition graft facilitating the revascularisation of lumbar artery perforator flap, (b) a schematic presentation of microsurgical anastomosis, with vein interposition grafting from the remnant lateral thoracic vein to resolve the short arterial length and the size discrepancy between the recipient and pedicle

Indian Journal of Plastic Surgery January-April 2016 Vol 49 Issue 1 


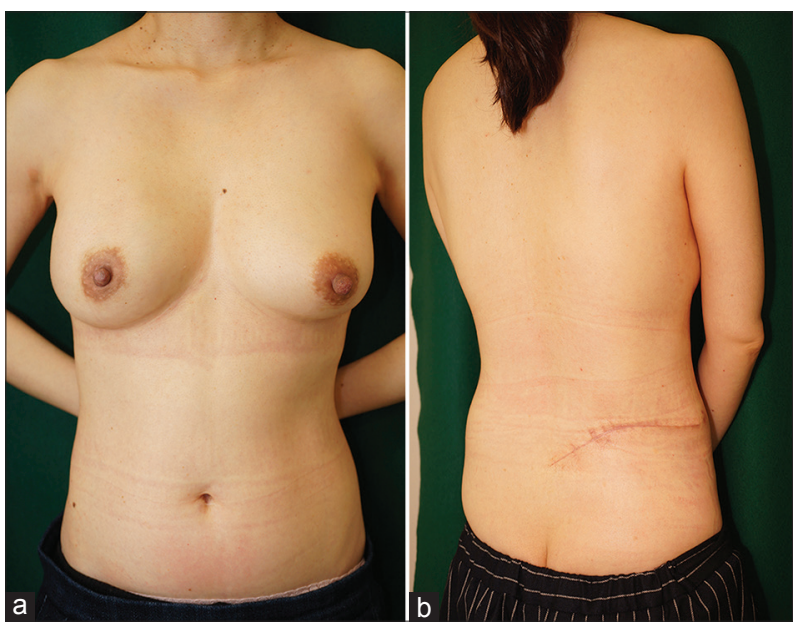

Figure 5: (a) Post-operative view of the reconstructed breast 6 months after surgery, (b) post-operative view of the donor site 6 months after surgery

preferred axillary approach for patients with DCIS is ordinarily SNB, which preserves the lateral thoracic vessels. The shortcomings include that the recipient lateral thoracic vessels are smaller than the thoracodorsal vessels, contain five types of variable branching patterns and in $3.33 \%$ of the patients, the lateral thoracic artery is completely absent. ${ }^{[9]}$ So far, lateral thoracic vessels have rarely been the choice for the recipient vessels. However, we believe that they are particularly preferable for short and small pedicle (LAP, GAP, SIEA and thigh perforator) flaps. This is because these vessels are located on the serratus anterior muscle, which is more superficial to the thoracodorsal vessels. In addition, the remnant of the lateral thoracic vein can be used as an interposition graft to adjust for discrepancy in pedicle length and size between the recipient and donor artery.

\section{CONCLUSION}

Despite the short pedicle of LAP flaps, our case demonstrated that using the lateral thoracic vessel as the recipient vessel together with a vein interposition graft can facilitate revascularisation of LAP flap and medialisation of the reconstructed breast to make a natural decollete line and cleavage because these recipient vessels are located on the serratus muscle just lateral to the pectoral border.

\section{Financial support and sponsorship Nil.}

\section{Conflicts of interest}

There are no conflicts of interest.

\section{REFERENCES}

1. de Weerd L, Elvenes OP, Strandenes E, Weum S. Autologous breast reconstruction with a free lumbar artery perforator flap. Br J Plast Surg 2003;56:180-3.

2. Peters KT, Blondeel PN, Lobo F, van Landuyt K. Early experience with the free lumbar artery perforator flap for breast reconstruction. J Plast Reconstr Aesthet Surg 2015;68:1112-9.

3. Kato $\mathrm{H}$, Hasegawa M, Takada T, Torii S. The lumbar artery perforator based island flap: Anatomical study and case reports. Br J Plast Surg 1999;52:541-6.

4. de Weerd L, Weum S. The butterfly design: Coverage of a large sacral defect with two pedicled lumbar artery perforator flaps. Br J Plast Surg 2002;55:251-3.

5. Offman SL, Geddes CR, Tang M, Morris SF. The vascular basis of perforator flaps based on the source arteries of the lateral lumbar region. Plast Reconstr Surg 2005;115:1651-9.

6. Lui KW, Hu S, Ahmad N, Tang M. Three-dimensional angiography of the superior gluteal artery and lumbar artery perforator flap. Plast Reconstr Surg 2009;123:79-86.

7. Kiil BJ, Rozen WM, Pan WR, Grinsell D, Ashton MW, Corlett RJ, et al. The lumbar artery perforators: A cadaveric and clinical anatomical study. Plast Reconstr Surg 2009;123:1229-38.

8. Regolo L, Ballardini B, Gallarotti E, Scoccia E, Zanini V. Nipple sparing mastectomy: An innovative skin incision for an alternative approach. Breast 2008;17:8-11.

9. Loukas M, du Plessis M, Owens DG, Kinsella CR Jr., Litchfield CR, Nacar A, et al. The lateral thoracic artery revisited. Surg Radiol Anat 2014;36:543-9. 